\title{
An update on management of renal colic
}

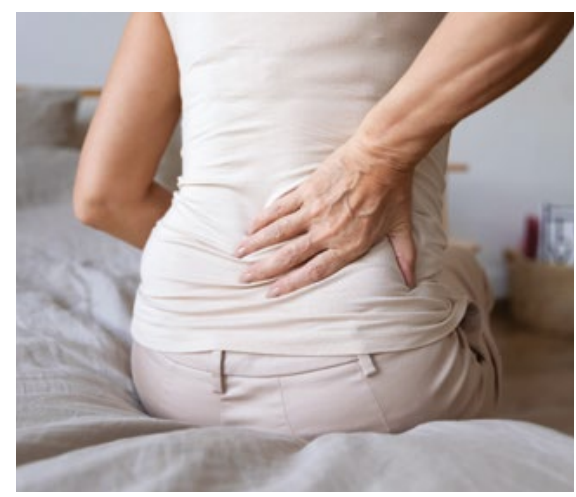

CPD

Ivan Thia, Manmeet Saluja

\section{Background \\ Renal tract pain is a common presentation in the primary care setting that can masquerade as other abdominopelvic conditions, and vice versa. A stepwise approach to a patient with renal tract pain can aid immensely in formulating an accurate diagnosis and providing optimal care.}

\section{Objective}

The aim of this article is to present current evidence-based recommendations for renal tract pain to assist in its diagnosis, assessment and management.

\section{Discussion}

Renal tract pain is mediated by a surge in prostaglandin release, leading to arterial vasodilatation, increased vascular permeability, and subsequently ureteric oedema and spasms. Referred and migratory pain are hallmarks of this condition and are unique to renal colic because of the progressive passage of the stone along the ureter. Diagnosis requires a stepwise approach with history-taking, assessment, blood tests and imaging. Successful management of renal tract pain necessitates a combination of analgesia and medical expulsive therapy, failing which surgical intervention is required.
RENAL TRACT PAIN is a common presentation to a general practitioner (GP) or emergency department, accounting for approximately $75 \%$ of presentations due to disorders of the genitourinary system. ${ }^{1}$ Ureteric calculi causing obstruction are among the most commonly identifiable causes. One in 10 Australians will have kidney stones in their lifetime. ${ }^{2}$ Recurrence of renal stones within five years approaches 50\%; ${ }^{2}$ however, $75-90 \%$ of renal calculi pass spontaneously without intervention. $^{3}$

The aim of this article is to present current evidence-based recommendations for the acute management of renal colic. Its pathophysiology, investigations, diagnosis and therapeutic options are important considerations for GPs in the acute setting.

\section{Discussion}

Renal tract pain can be caused by acute ureteric obstruction, pedicle traction or stretching/compression of the peripelvic renal capsule or renal pelvis. ${ }^{4}$ Severity of renal colic is associated with acuity rather than degree of obstruction. ${ }^{5}$

Renal colic occurs in predictable phases, reaching maximum intensity in 30-120 minutes and usually lasting for 3-18 hours.
The three phases are:

- acute - insidious, constant, intermittent exacerbations that crescendo up to six hours

- constant - sustained maximal pain intensity, lasting 1-4 hours

- relief - gradual diminishment, lasting 1-3 hours.

To understand renal tract pain, two concepts must be explored - the migratory nature of renal tract pain, and referred pain.

Sensory innervation over the entire length of the ureter is fed back to the sympathetic autonomic nervous system through T10-L2. ${ }^{6}$ Renal colic pain is migratory depending on the location of the offending calculus, resulting in the classic 'loin to groin' pain. When a renal calculus advances into the ureter, ureteric spasms occur secondary to a massive release of prostaglandins. ${ }^{7}$ Renal stones in the upper two-thirds of the ureter tend to present with flank and renal angle tenderness. As they progress into the distal third of the ureter, patients tend to experience pain in the groin, labia/scrotum or perineum. This may be associated with storage-related lower urinary tract symptoms (LUTS), such as urinary frequency, urgency, nocturia and incontinence. ${ }^{8}$ None of the aforementioned symptoms reliably predicts the location of the offending stone in the ureter. 
Referred pain is pain perceived by the body at a location other than the site of the painful stimulus. ${ }^{9}$ General visceral afferent pain fibres travel with sympathetic fibres back to the spinal cord segments that gave rise to the preganglionic sympathetic fibres. ${ }^{10}$ This is difficult to distinguish from pain travelling along dermatomes that occupy the same spinal root segment dorsal ganglia. Given their varied presentations, various extra-urinary diseases can masquerade as ureteric disorders and vice versa. Table 1 lists some important causes and mimickers of renal tract pain.

\section{Assessment of renal tract pain History-taking}

History-taking is important as many factors predispose individuals to the formation of renal calculi, and it should include:

- personal or family history of renal stones

- known structural renal tract abnormalities - horseshoe, ectopic or medullary sponge kidneys; pelviureteric junction obstruction; polycystic kidney disease; pyelo-ureteral duplication ${ }^{11}$

- medical conditions - gout, hyperparathyroidism, renal tubular acidosis, osteoporosis, recurrent urinary tract infections

- medications - loop diuretics, carbonic anhydrase inhibitors, ciprofloxacin, sulfonamide-containing medications, indinavir ${ }^{12}$

- dehydration, high salt and protein intake. Associated symptoms during examination can often help to distinguish one diagnosis from another. Haematuria is a common feature of ureteric calculi and is associated with approximately $82 \%$ of renal colic presentations. ${ }^{13}$ Nausea and vomiting as well as LUTS often accompany renal colic. Concomitant fevers might be indicative of other inflammatory or infective processes or signal the presence of an infected obstructed kidney, which is a urological emergency. A comprehensive examination of all abdominopelvic organ systems is essential to rule out other important life-threatening conditions. A diagnosis of renal colic does not exclude other concomitant medical conditions that may require more urgent attention.

\section{Investigations}

Bedside and laboratory tests for suspected renal colic patients should include the following: ${ }^{14}$

- urine dipstick analysis/urine culture

- beta human chorionic gonadotropin

\section{Table 1. Causes and mimickers of renal tract pain ${ }^{6}$}

\begin{tabular}{|c|c|}
\hline Renal & $\begin{array}{l}\text { - Inflammation - pyelonephritis, renal/perinephric abscess } \\
\text { - Tumour - renal cell carcinoma } \\
\text { - Vascular - thrombosis, trauma } \\
\text { - Obstruction - renal calculi }\end{array}$ \\
\hline Ureter & $\begin{array}{l}\text { - Intrinsic - calculi, blood clot, papillary necrosis, stricture, malignancy } \\
\text { (ureteric urothelial cancer, prostate adenocarcinoma invading ureter) } \\
\text { - Congenital - pelviureteric junction obstruction, vesicoureteric reflux } \\
\text { - latrogenic - instrumentation, trauma } \\
\text { - Extrinsic - lymphadenopathy/malignancy, retroperitoneal fibrosis }\end{array}$ \\
\hline Testis & $\begin{array}{l}\text { - Inflammation - epididymo-orchitis, testicular torsion, epididymal cyst } \\
\text { infection, hydrocele } \\
\text { - Tumour - testicular cancer } \\
\text { - Vascular - varicocele }\end{array}$ \\
\hline Extra-urinary & $\begin{array}{l}\text { - Inflammation - appendicitis, cholecystitis, diverticulitis, pelvic } \\
\text { inflammatory disease } \\
\text { - Vascular - aortic and iliac aneurysms } \\
\text { - Inguinal hernias, ovarian pathology, ectopic pregnancy }\end{array}$ \\
\hline
\end{tabular}

- full blood examination

- C-reactive protein

- urea, electrolyte, creatinine.

In conjunction with individual patient (eg age, comorbidities, renal function) and disease (stone, duration) factors, these investigations are important in helping to identify a subset of patients who are not suitable for conservative management, especially if there are markedly raised inflammatory markers or severe renal failure in the absence of other infections/ inflammatory conditions.

Diagnostic imaging is also important in the workup of renal tract pain (Figure 1). Immediate imaging is indicated in vulnerable patient populations (eg those with infective symptoms, a single kidney or severe renal failure). ${ }^{15}$ Low-dose, non-contrast computed tomography (CT) of the kidneys, ureters and bladder (KUB) is the current gold-standard imaging of choice and can readily identify stone location, size and density. ${ }^{16}$ It is also useful in diagnosing most mimickers within captured surrounding anatomy. A meta-analysis of non-contrast CT diagnoses of renal tract calculi has demonstrated a pooled sensitivity of $93.1 \%$ and specificity of $96.6 \% .{ }^{17}$ In patients with a body mass index $<30 \mathrm{~kg} / \mathrm{m}^{2}$, sensitivity for detection of stones $>3 \mathrm{~mm}$ in size is $100 \% .^{18}$

In younger individuals (ie those aged $<50$ years) and those more susceptible to radiation risk, such as pregnant women, KUB ultrasonography is a useful alternative first-line imaging tool to identify calculi present in the renal calyx, pelvis, proximal and distal ureter. KUB ultrasonography can also readily pick up hydroureter and hydronephrosis suggestive of a ureteral obstructive process. ${ }^{19}$ However, it is markedly less useful in identifying calculi in the mid ureter because of overlying bowel gas. KUB ultrasonography is also highly dependent on operator skill and patient factors such as body habitus. Overall, KUB ultrasonography is safe, reproducible and inexpensive, with acceptable calculi detection rates for both renal (sensitivity $45 \%$, specificity $88 \%$ ) and ureteric (sensitivity $45 \%$, specificity $94 \%$ ) calculi. ${ }^{19}$ When results are 
inconclusive, or in the event of persistent symptoms or ongoing suspicion of renal colic, a CT scan should be performed, especially if surgical intervention may be required.

\section{Management of renal tract pain \\ Pain relief}

Paracetamol and nonsteroidal

anti-inflammatory drugs (NSAIDs)

have been shown to be effective in the treatment of renal colic and are superior to opioid medications in terms of analgesic efficacy. ${ }^{20}$ Less rescue analgesia is required for breakthrough pain or recurrent renal colic with the use of NSAIDs than with opioid medications. ${ }^{21}$ The current understanding of the mechanism behind this is that the increased release of prostaglandins secondary to ureteric obstruction promotes glomerular afferent arteriolar dilatation and increased vascular permeability. ${ }^{22}$ This leads to increased urine output from the affected kidney and higher renal pelvic pressure. NSAIDs exert their effect primarily by reducing prostaglandin production, thereby reducing the glomerular filtration rate by as much as $35 \%$, thus reducing renal pelvic pressures and stimulation of stretch receptors. ${ }^{23,24}$ Ureteric oedema improves as well, enabling better drainage and reducing ureteric spasms. There is also some evidence that NSAIDs exert a direct effect on local ureteric smooth muscle, mediating relaxation. ${ }^{24}$

NSAIDs are also versatile, available in many formulations for rapid effect, such as oral, intravenous and per rectal formulations. Per rectal administration of NSAIDs may provide better symptomatic control as there is an increased local anti-inflammatory effect. ${ }^{25}$

NSAIDs can worsen acute renal failure in patients with underlying chronic renal failure when taken for renal colic and should be used with caution and for short periods of time only. In general, NSAIDs should be used at the lowest dose for the shortest period required to minimise NSAID-induced nephropathy. ${ }^{26}$

Opioid medications should be used as second-line analgesia if NSAIDs are contraindicated or insufficient in pain control. They tend to provide only short-term relief and require multiple dosing to achieve the desired effect. Opioid medications are also associated with a less favourable side-effect profile including nausea, vomiting, sedation, respiratory depression and constipation with increasing duration of use. ${ }^{27}$

Combination therapy of opioids with paracetamol and NSAIDs achieves synergistic effects, better pain control and fewer side effects through opioid sparing. ${ }^{27}$

\section{Medical expulsive therapy}

Medical expulsive therapy (MET) has been studied extensively to determine whether it reduces interval time for

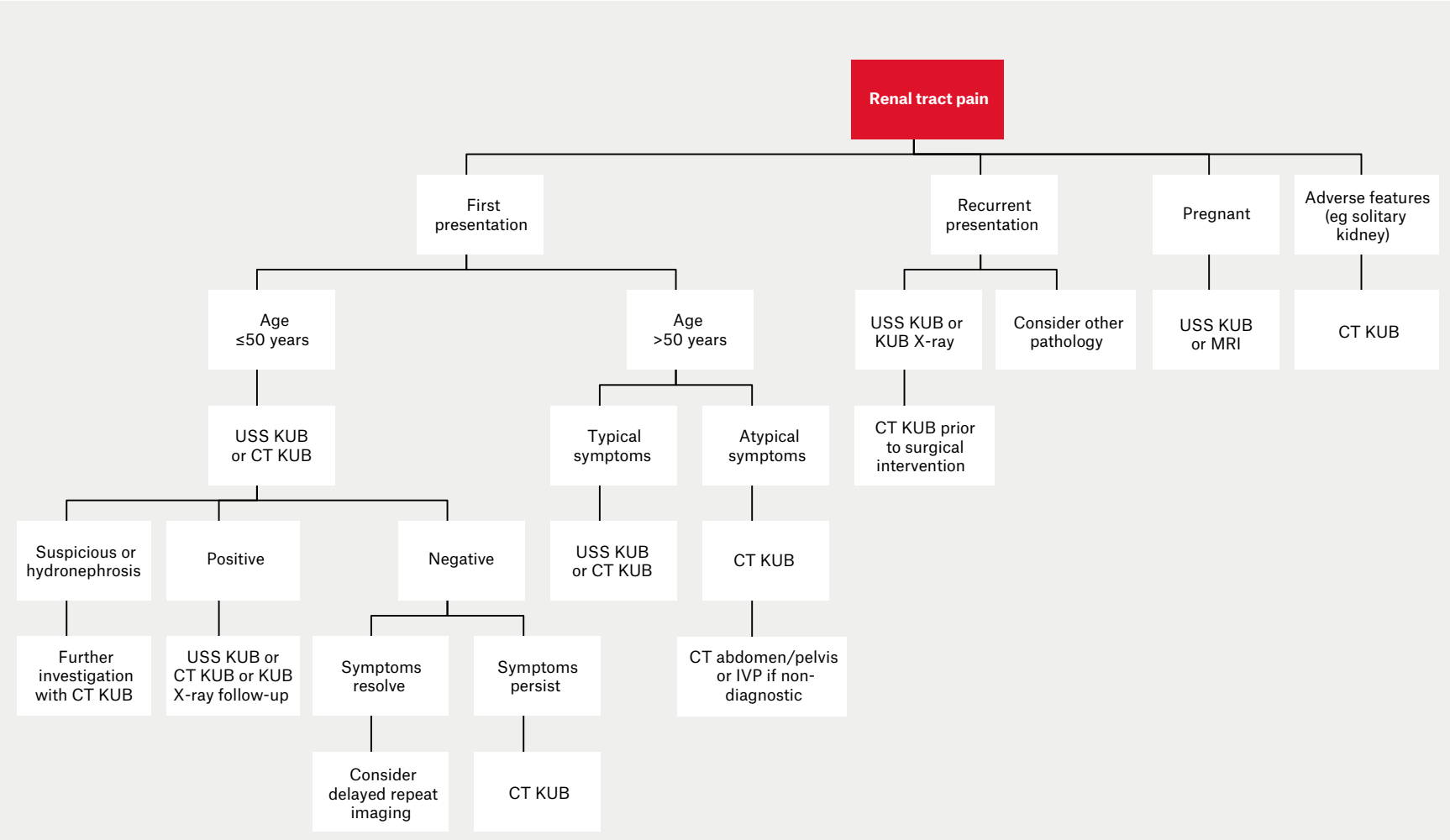

Figure 1. Diagnostic imaging pathway of renal tract pain ${ }^{37}$

CT, computed tomography; IVP, intravenous pyelogram; KUB, kidneys, ureters and bladder; MRI, magnetic resonance imaging; USS, ultrasonography 
passage of stones if surgical intervention is not immediately indicated. This follows the discovery that $\alpha$-adrenergic receptors are present in high density along the distal ureter. ${ }^{28}$ Several medications have been trialled, including $\alpha$-blockers, calcium channel blockers, steroids and phosphodiesterase type 5 (PDE5) inhibitors. ${ }^{29}$ The theory was that medications that could relax ureteral smooth muscle without losing peristalsis or reduce ureteral oedema would hasten passage of stones into the bladder.

Tamsulosin has been shown to be superior to calcium channel blockers and PDE5 inhibitors in several small studies. ${ }^{30}$ Indeed, $\alpha$-blockers as a class have been evaluated in a meta-analysis and were found to increase rate of stone expulsion (risk ratio: 1.54, 95\% confidence interval: $1.29,1.85 ; P<0.01),{ }^{30}$ reduce time to expulsion $(P<0.01)$, reduce analgesia use and relieve renal colic $(P<0.01){ }^{31}$ Tamsulosin, the most widely studied in the class, proved to be more efficacious for larger stones ( $>5 \mathrm{~mm}$ ) and stones within the distal segment of the ureter that were amenable to conservative management. ${ }^{32}$ The most common reported side effect associated with the use of tamsulosin was transient postural hypotension (4.2\%). ${ }^{33}$ A newer, more selective medication of the same class includes silodosin $(\alpha 1 \mathrm{~A})$, while naftopidil ( $\alpha 1 \mathrm{D})$ also shows great promise. ${ }^{34}$ Studies have been conducted using $\alpha$-blockers post-surgical intervention (eg laser lithotripsy and extracorporeal shock wave lithotripsy) to aid in passage of residual stone fragments with some success. ${ }^{35}$

\section{Surgical intervention}

Renal colic failing medical treatment, stones associated with anuria (eg single kidney or bilateral obstruction), acute renal failure or concomitant infection would require surgical decompression of the affected kidney(s). Options include cystoscopic retrograde stent insertion or nephrostomy tube insertion with or without antegrade stenting. There is no current good evidence to support one intervention over the other. ${ }^{36}$ If there is no evidence of infection, it is feasible to attempt a primary laser lithotripsy of the offending calculus, although success rates are lower with larger, more proximally situated calculi. ${ }^{3}$

\section{Conclusion}

Renal tract pain is a common presentation in the primary care setting. Accurate diagnosis and early initiation of adequate analgesia and medical expulsive therapy in appropriate patient groups can help improve quality of patient care and reduce emergency department presentations and healthcare costs.

\section{Key points}

- Renal tract pain is a common presentation in the primary care setting that can masquerade as other abdominopelvic conditions, and vice versa.

- Understanding the underlying pathophysiology will help in its diagnosis.

- Clinical assessment, blood tests and imaging should be included in the diagnostic process.

- Optimum management includes a combination of adequate analgesia and medical expulsive therapeutic options.

- A large percentage of renal calculi can be managed conservatively; surgical intervention is only required in the first instance when red flag symptoms are present.

\section{Authors}

Ivan Thia MBBS, Surgical Registrar, Department of Urology, Royal Perth Hospital, WA

Manmeet Saluja MBChB, FRACS (Urology), Urologist, Department of Urology, Royal Perth Hospital, WA

Competing interests: None.

Funding: None.

Provenance and peer review: Commissioned, externally peer reviewed.

Correspondence to:

ivan.thia@health.wa.gov.au

\section{References}

1. Australian Institute of Health and Welfare. Media release: Emergency department care. Bruce, ACT: AlHW, 2020. Available at www.aihw.gov.au/ reports-data/myhospitals/sectors/emergencydepartment-care [Accessed 16 April 2021]

2. Pathan SA, Mitra B, Bhutta ZA, et al. A comparative, epidemiological study of acute renal colic presentations to emergency departments in Doha, Qatar, and Melbourne, Australia. Int J Emerg Med 2018;11(1):1. doi: 10.1186/s12245-017-0160-9.
3. Jendeberg J, Geijer H, Alshamari M, Cierzniak B, Lidén M. Size matters: The width and location of a ureteral stone accurately predict the chance of spontaneous passage. Eur Radiol 2017;27(11):4775-85. doi: 10.1007/s00330-0174852-6.

4. Dewar MJ, Chin JL. Chronic renal pain: An approach to investigation and management. Can Urol Assoc J 2018;12(6Suppl 3):S167-S70. doi: 10.5489/cuaj.5327.

5. Shokeir AA. Renal colic: Pathophysiology, diagnosis and treatment. Eur Urol 2001;39(3):241-49. doi: 10.1159/000052446.

6. Bueschen AJ. Flank pain. In: HK Walker, WD Hall, JW Hurst, editors. Clinical methods: The history, physical, and laboratory examinations. 3rd edn. Boston, MA: Butterworths, 1990; p. 845-46.

7. Portis AJ, Sundaram CP. Diagnosis and initial management of kidney stones. Am Fam Physician 2001;63(7):1329-39.

8. Menon M, Parulkar BG, Drach GW. Urinary lithiasis: Etiology, diagnosis and medical management. In: Walsh PC, Retik AB, Vaughan ED Jr, Wein AJ, editors. Campbell's urology. 7th edn. Philadelphia, PA: WB Saunders, 1998; p. 2661-733.

9. Heilberg IP, Schor N. Renal stone disease: Causes, evaluation, medical treatment. Arq Bras Endocrinol Metabol 2006;50(4):823-31. doi: 10.1590/s0004-27302006000400027.

10. Carlson BM. Human embryology and developmental biology. 3rd edn. St Louis, MO: Mosby, 2004.

11. Clapp WL. Renal anatomy. In: Zhou XJ, Laszik Z, Nadasdy T, D'Agati VD, Silva FG, editors. Silva's diagnostic renal pathology. New York, NY: Cambridge University Press, 2009; p. 1-46.

12. Matlaga BR, Shah OD, Assimos DG. Drug-induced urinary calculi. Rev Urol 2003;5(4):227-31.

13. Mefford JM, Tungate RM, Amini L, et al. A comparison of urolithiasis in the presence and absence of microscopic haematuria in the emergency department. West J Emerg Med 2017;18(4):775-79. doi: 10.5811/ westjem.2017.4.33018.

14. Jindai G, Ramachandani P. Acute flank pain secondary to urolithasis: Radiologic evaluation and alternate diagnoses. Radiol Clin North Am 2007;45(3):395-410, vii. doi: 10.1016/j. rcl.2007.04.001.

15. Wimpissinger F, Türk $C$, Kheyfets $O$, Stackl W. The silence of the stones: Asymptomatic ureteral calculi. J Urol 2007;178(4 Pt 1):1341-44; discussion 1344. doi: 10.1016/j.juro.2007.05.128.

16. Heidenreich A, Desgrandschamps F, Terrier F. Modern approach of diagnosis and management of acute flank pain: Review of all imaging modalities. Eur Urol 2002;41(4):351-62. doi: 10.1016/s0302-2838(02)00064-7.

17. Worster A, Preya I, Weaver B, Haines T. The accuracy of noncontrast helical computed tomogaphy versus intravenous pyelography in the diagnosis of suspected acute urolithiasis: A metaanalysis. Ann Emerg Med 2002;40(3):280-86. doi: 10.1067/mem.2002.126170.

18. Zheng X, Liu Y, Li M, Wang Q, Song B. Dualenergy computed tomography for characterizing urinary calcified calculi and uric acid calculi: A meta-analysis. Eur J Radiol 2016;85(10):1843-48. doi: 10.1016/j.ejrad.2016.08.013.

19. Smith-Bindman R, Aubin C, Bailitz J, et al. Ultrasonography versus computed tomography for suspected nephrolithiasis. N Engl J Med 2014;371(12);1100-10. doi: 10.1056/ NEJMoa1404446. 
20. Pathan SA, Mitra B, Straney LD, et al. Delivering safe and effective analgesia for management of renal colic in the emergency department: A double-blind multigroup, randomised controlled trial. Lancet 2016;387(10032):1999-2007. doi: 10.1016/S0140-6736(16)00652-8.

21. Pathan SA, Mitra B, Cameron PA. A systematic review and meta-analysis comparing the efficacy of nonsteroidal anti-inflammatory drugs, opioids, and paracetamol in the treatment of acute renal colic. Eur Urol 2018;73(4):583-95. doi: 10.1016/j. eururo.2017.11.001.

22. Cole RS, Fry $\mathrm{CH}$, Shuttleworth KE. The action of the prostaglandins on isolated human ureteric smooth muscle. Br J Urol 1988;61(1):19-26. doi: 10.1111/j.1464-410x.1988.tb09155.x.

23. Perlmutter A, Miller L, Trimble LA, Marion DN, Vaughan ED Jr, Felsen D. Toradol, an NSAID used for renal colic, decreases renal perfusion and ureteral pressure in a canine model of unilateral ureteral obstruction. J Urol 1993;149(4):926-30. doi: 10.1016/s0022-5347(17)36261-4.

24. Sivrikaya A, Celik OF, Sivrikaya N, Ozgur GK. The effect of diclofenac sodium and papaverine on isolated human ureteric smooth muscle. Int Urol Neph 2003;35:479-83. doi: 10.1023/b:urol.00000 25618.68752.5b.

25. Davenport K, Waine E. The role of nonsteroidal anti-inflammatory drugs in renal colic. Pharmaceuticals (Basel) 2010;3(5):1304-10 doi: 10.3390/ph3051304.

26. Schjerning Olsen AM, Fosbøl EL, Lindhardsen J, et al. Duration of treatment with nonsteroidal antiinflammatory drugs and impact on risk of death and recurrent myocardial infarction in patients with prior myocardial infarction: A nationwide cohort study. Circulation 2011;123(20):2226-35. doi: 10.1161/CIRCULATIONAHA.110.004671.

27. Wood KD, Gorbachinsky I, Gutierrez J. Medical expulsive therapy. Indian J Urol 2014;30(1):60-64. doi: 10.4103/0970-1591.124209.

28. Dellabella M, Milanese G, Muzzonigro G. Randomized trial of the efficacy of tamsulosin, nifeipine and phloroglucinol in medical expulsive therapy for distal ureteral calculi. J Urol 2005;174(1):167-72. doi: 10.1097/01. ju.0000161600.54732.86.

29. Wang H, Man LB, Huang GL, Li GZ, Wang JW. Comparative efficacy of tamsulosin versus nifedipine for distal ureteral calculi: A metaanalysis. Drug Des Devel Ther 2016;10:1257-65. doi: 10.2147/DDDT.S99330.

30. Hollingsworth J, Canales BK, Rogers MA, et al. Alpha blockers for treatment of ureteric stones: Systematic review and meta-analysis. BMJ 2016;355:i6112. doi: 10.1136/bmj.i6112.

31. Pickard R, Starr K, MacLennan G, et al. Medical expulsive therapy in adults with ureteric colic: A multicentre, randomised, placebo-controlled trial. Lancet 2015;386(9991):341-49. doi: 10.1016/ S0140-6736(15)60933-3.

32. Ye Z, Zeng G, Yang H, et al. Efficacy and safety of tamsulosin in medical expulsive therapy for distal ureteral stones with renal colic: A multicenter, randomized, double-blinded, placebo-controlled trial. Eur Urol 2018;73(3):385-91. doi: 10.1016/j. eururo.2017.10.033.

33. Ding $H$, Ning $Z$, Dai $Y$, Shang $P$, Yang L. The role of Silodosin as a new medical expulsive therapy for ureteral stones: A meta-analysis. Ren Fail 2016;38(9):1311-19. doi: 10.1080/0886022X.2016.1215221.

34. Oestreich MC, Vernooij RW, Sathianathen NJ, et al. Alpha-blockers after shock wave lithotrip-sy for renal or ureteral stones in adults. Cochrane
Database Syst Rev 2020;11:CD013393. doi: 10.1002/14651858.CD013393.pub2.

35. Jessen JP, Breda A, Brehmer M, et al. International collaboration in endourology: Multicenter evaluation of prestenting for ureterorenoscopy. J Endourol 2016;30(3):268-73. doi: 10.1089/ end.2015.0109.

36. Assimos D, Crisci A, Culkin D, et al. Preoperative $\mathrm{JJ}$ stent placement in ureteric and renal stone treatment: Results from the clinical research office of endourological society (CROES) ureteroscopy (URS) global study. BJU Int 2016;117(4):648-54. doi: 10.1111/bju.13250.

37. Diagnostic Imaging Pathways. Diagnostic imaging pathways - Loin pain (renal colic). Perth, WA: Government of Western Australia, 2016. 